\title{
Performance of a Novel In Vitro Assay for Skin Sensitization Based on Activation of T Lymphocytes
}

\author{
Fenxia Hou, Caihong Xing, Bin Li, Juan Cheng and Wei Chen \\ Department of Toxicology, National Institute of Occupational Health and Poison Control, Chinese Center for Disease Control and Prevention, \\ Beijing, China
}

\begin{abstract}
There are currently no skin sensitization assays based on T cell activation. We built a novel in vitro test to assess $T$ cell activation and assessed its performance to discriminate skin sensitizers from non-sensitizers using 52 reference chemicals. Jurkat Clone E6-1 human T lymphocytes were exposed to a series of concentrations of test substances for 24 hours and CD69 expression was measured as a marker of early T cell activation by flow cytometry. Most sensitizers tested induced an increased relative fluorescence intensity (RFI) of CD69 on the T cells, which was linearly correlated with the tested concentrations, indicating a statistically significant causal link between sensitizer concentration and increase of CD69 expression. CD69 RFI $\geq 1.5$ was determined as the positive criterion for skin sensitizer classification when cell viability $\geq 50 \%$. The sensitivity $(79.4 \%)$, specificity $(88.9 \%)$ and accuracy $(82.7 \%)$ of our test for the 52 tested reference chemicals showed a good predictivity for skin sensitizers. Results were reproduced in at least two repeats, and the concurrent positive control, $2 \mu \mathrm{g} / \mathrm{mL}$ 2,4-dinitrochlorobenzene, was found positive in all 25 independent runs conducted, indicating in-house reproducibility. The EC1.5 value, i.e., the concentration at which a test chemical induces a CD69 RFI of 1.5, may be used to categorize skin sensitization potency of a chemical. This work may contribute to the development of an in vitro assay for skin sensitization based on the activation of T cells.
\end{abstract}

\section{Introduction}

Skin sensitization is one of the key adverse effects that many chemicals possess. Identifying the hazard of skin sensitization of new chemicals is demanded under health regulations worldwide. Animal assays that can be used to predict whether chemicals cause skin sensitization are the guinea pig maximization test, the Buehler test (OECD, 1992), and the murine local lymph node assay (LLNA) (OECD, 2010a,b,c). During the last decade, intensive work has been done to develop in vitro assays for skin sensitization to replace animal testing with non-animal methods (EU, 2009; Casey, 2016).

To contribute to the development of in vitro assays for skin sensitization, the adverse outcome pathway (AOP) for skin sensitization was described (OECD, 2012). The AOP contains four key events (KEs). Currently, the Organization for Economic Co-operation and Development (OECD) has developed and adopted several assays for skin sensitization based on the first three of the four AOP KEs (OECD, 2015a,b, 2018). However, the OECD has not formally adopted any in vitro assay representing the fourth KE yet. In addition, it is consistently argued that a single in vitro assay for skin sensitization is not sufficient to substitute testing in an animal model (e.g., the LLNA). Instead, combination of in vitro methods into integrated approaches to testing and assessment (IATA) will be required (Jowsey et al., 2006; Corsini et al., 2014; Reisinger et al., 2015; Ezendam et al., 2016; Jaworska, 2016; Strickland et al., 2016). The integration of information derived from assays for the first three of the four AOP KEs for the skin sensitization AOP already is the basis for several defined approaches (DA) to be used in IATA (OECD, 2016). Additional data on the fourth KE for the skin sensitization AOP may provide useful complementary information to complete the development of AOP-based DAs and IATAs and improve current predictive parameters.

The fourth KE of the AOP for skin sensitization relates to the activation of naïve $T$ cells and proliferation of antigen-specific
Received January 31, 2020; Accepted April 21, 2020 ;

Epub April 21, 2020; @ The Authors, 2020.

ALTEX 37(3), 451-468. doi:10.14573/altex.2001312

Correspondence: Fenxia Hou, MD

Department of Toxicology

National Institute of Occupational Health and Poison Control

Chinese Center for Disease Control and Prevention

Nan Wei road 29, 100050 Beijing, China

(houfenxia66@163.com)
This is an Open Access article distributed under the terms of the Creative Commons Attribution 4.0 International license (http://creativecommons.org/licenses/by/4.0/) which permits unrestricted use, distribution and reproduction in any medium, provided the original work is appropriately cited. 
effector and memory T cells (OECD, 2012). It plays a key role in the AOP. However, it represents a complex biological process. In short, two types of signal that act synergistically are required for full activation of naïve T lymphocytes. Binding of antigenic peptides to $\mathrm{MHC}$ molecules presented by antigen-presenting cells (APC) to T cell receptors (TCR) on the T cells provides the first signal. The second signal results from the interaction of costimulatory receptors on T cells with their ligands on the APCs. The best characterized costimulatory molecule is CD28. Its ligands are CD80 and CD86 on APCs (June et al., 1990; Robey and Allison, 1995; Chakraborty and Weiss, 2014). In addition, cytokines are essential for $\mathrm{T}$ cell activation. For example, IL- $1 \alpha$, IL- $1 \beta$, IL-18 and TNF- $\alpha$ are needed for APCs to migrate from the epidermis to the dermis of the skin and then to the proximal lymph nodes, where they present the hapten-protein complex to T-cells; IL-2 is needed for full T cell activation (OECD, 2012). The complexity of the processes makes it difficult to perfectly model the process in vitro. A consensus report of a recent Cosmetics Europe Workshop (van Vliet et al., 2018) comprehensively discussed the state-of-the-art of the assays that have been developed to assess $\mathrm{T}$ cell activation by skin sensitizers. It concluded that although a number of T cell-based assays (Dietz et al., 2010; Richter et al., 2013; Vocanson et al., 2014; Ahmed et al., 2016) currently show encouraging test results in predicting the immunogenic potential of chemicals, they are time-consuming, laborious and expensive, and also have donor-to-donor variability. Further intensive research is required to solve these problems. The review indicates that it is currently difficult to anticipate the use of T cell assay data for safety assessment.

In this study, a new in vitro test to assess $\mathrm{T}$ cell activation by skin sensitizers is investigated to contribute to the development of in vitro assays for skin sensitization corresponding to the fourth KE. The cluster of differentiation 69 (CD69) is a glycoprotein expressed on the T cell surface triggered by TCR activation (Testi et al., 1989; Ziegler et al., 1994; Cimo et al., 2013). Expression of CD69 on the surface of T lymphocytes is considered a marker of early T cell activation (D'Ambrosio et al., 1994; Ziegler et al., 1994; Taylor-Fishwick and Siegel, 1995; Morgan et al., 1999; Green et al., 2003; Cimo et al., 2013; Dimitrova et al., 2018; Klug et al., 2019). Immune sensitization therefore could induce an increase in CD69 expression on T lymphocytes (Swirski et al., 2002; Konrad et al., 2004; Avgustin et al., 2005; Bavandi et al., 2006; Beeler et al., 2008; Zahid et al., 2019; Koren et al., 2019).

The Jurkat Clone E6-1 human T lymphocyte is an immortal cell line often used in studies on in vitro human $\mathrm{T}$ cell activation (Fernández-Riejos et al., 2008; Pan et al., 2015; Ngo et al., 2017; Chen et al., 2018; Vis et al., 2018; Colin-York et al., 2019; Kim et al., 2019). It has been reported that for some chemicals that incubating them in vitro with the Jurkat T cells in culture medium induced early $\mathrm{T}$ cell activation manifesting as an increase in CD69 expression on the Jurkat T cells in the absence of APCs in the test system (Fernández-Riejos et al., 2008; Chen et al., 2018; Vis et al., 2018).

Based on these reports, a novel in vitro $\mathrm{T}$ cell-based test to predict skin sensitization of chemicals was developed. Briefly,
Jurkat Clone E6-1 human T lymphocytes are exposed to test substances for $24 \mathrm{~h}$ and changes of CD69 expression on the T cells are determined using flow cytometry. As a proof of principle, the skin sensitizers 2,4-dinitrochlorobenzene, 4-phenylenediamine and cobalt chloride were shown to cause an increase in CD69 expression in pilot experiments. Here, we evaluated the predictive performance of the test system to identify skin sensitizers using 52 reference chemicals.

\section{Materials and methods}

\section{Chemicals}

A total of 52 chemicals were tested of which 34 are sensitizers and 18 are non-sensitizers. All chemicals have been evaluated in the LLNA (Ashby et al., 1993; ICCVAM, 1999, 2010; Basketter et al., 2012; Urbisch et al., 2016), and they include many of the most commonly used reference substances for testing in vitro assays for skin sensitization (Sens-it-iv, 2009; Chipinda et al., 2011; Hennen et al., 2011; Emter et al., 2010; Nukada et al., 2012, 2013). They are listed, together with the suppliers from whom they were purchased and the concentrations tested, in Table 1 . The vehicle, dimethyl sulfoxide (DMSO) (ultra-pure, product no.: N182-5×10-ML) was purchased from Amresco.

\section{Cells and cell culture}

The immortal cell line Jurkat Clone E6-1 human T lymphocyte was purchased from BeNa Culture Collection (Beijing, China). Cells were cultured in $75 \mathrm{~mL}$ or $100 \mathrm{~mL}$ culture flasks at $37^{\circ} \mathrm{C}$ under $5 \% \mathrm{CO}_{2}$ and humidified atmosphere in RPMI 1640 supplemented with $5 \mathrm{mM}$ HEPES, $2 \mathrm{mM}$ L-glutamine, 10\% heat-inactivated fetal bovine serum (Corning, Cellgro, New Zealand, product no.: 35-081-CV) and 1\% penicillin-streptomycin (Invitrogen Corp., product no.:15140122). The cells were seeded every 2 days at a density of $2 \times 10^{5}$ cells $/ \mathrm{mL}$. The passage numbers used for the test were between 5 and 30. The identity of the Jurkat Clone E6-1 human T lymphocyte used in this study was confirmed via the human STR profiling cell authentication service provided by $\mathrm{BeNa}$ Culture Collection (Beijing, China). The cells were tested negative for mycoplasma contamination by the supplier by a method of bioluminescence (luciferase) to test the enzymes specific for mycoplasma before this study was begun (Mycoplasma Detection Kit, LM009, Shanghai Yise Medical Technology Co., Ltd., Shanghai, China). All procedures for cell manipulation in this study strictly followed the good laboratory practice for sterile techniques of our laboratory.

\section{Test concentrations and treatment of the cells}

The concentrations tested for each chemical are shown in Table 1. They were selected mainly by conducting preliminary tests to determine concentrations that could induce a positive result with appropriate cell viability. The concentrations tested in the formal testing were at least three concentrations at 1.2-fold, 1.5-fold or 2 -fold serial dilutions. The highest concentration for each chemical should not cause a drop in cell viability to less than $50 \%$. The vehicle for nickel sulfate, nickel chloride, and sodium lauryl sul- 
Tab. 1: The test substances and concentrations tested

\begin{tabular}{|c|c|c|c|c|c|}
\hline Chemicals & $\begin{array}{l}\text { CAS } \\
\text { number }\end{array}$ & $\begin{array}{l}\text { Physical } \\
\text { form }\end{array}$ & Supplier & Concentrations tested $(\mu \mathrm{g} / \mathrm{mL})$ & $\begin{array}{l}\text { LLNA } \\
\text { potency } \\
\text { category }\end{array}$ \\
\hline \multicolumn{6}{|l|}{34 sensitizers } \\
\hline Oxazolone ${ }^{b, c}$ & $15646-46-5$ & $S$ & Alfa Aesar & $250,200,167,139$ & extreme \\
\hline $\begin{array}{l}\text { 5-Chloro-2-methyl-4- } \\
\text { isothiazolin-3-one a,c }\end{array}$ & $26172-55-4$ & $\mathrm{~L}$ & Aladdin & $1.8,1.5,1,0.67,0.44,0.30$ & extreme \\
\hline$p$-Benzoquinone ${ }^{c}$ & $106-51-4$ & $\mathrm{~S}$ & SCR & $4,3.33,2.78,2.31$ & extreme \\
\hline 2,4-Dinitrochlorobenzene ${ }^{a, b, c}$ & $97-00-7$ & $\mathrm{~S}$ & SCR & $2,1.33,0.89,0.59,0.40$ & extreme \\
\hline 4-Nitrobenzyl bromide b,c & $100-11-8$ & $\mathrm{~S}$ & Aladdin & $2.1,0.5,0.3,0.25,0.21,0.17$ & extreme \\
\hline Benzo[a]pyrene & $50-32-8$ & S & Aladdin & $60,50,41.7,34.7,28.9,24.1,20.1,16.7$ & extreme \\
\hline Glutaraldehyde b,c & $111-30-8$ & $\mathrm{~L}$ & SCR & $3.3,2.2,1.5,1.0$ & strong \\
\hline 4-Phenylenediamine ${ }^{a, b, c}$ & $106-50-3$ & $S$ & SCR & $5,4.17,3.47,2.89,2.41$ & strong \\
\hline Formaldehyde $^{c}$ & $50-00-0$ & $\mathrm{~L}$ & SCR & $4.8,4.0,3.33,2.78,2.31,1.93$ & strong \\
\hline Cobalt chloride ${ }^{a, c}$ & $7646-79-9$ & $\mathrm{~S}$ & Urchem & $80,66.7,55.6,46.3,38.6,32.1$ & strong \\
\hline 4-Methylaminophenol sulfate ${ }^{c}$ & $55-55-0$ & S & $\mathrm{TCl}$ & $4,3.3,2.78,2.31,1.93$ & strong \\
\hline Tetramethylthiuram disulfide $\mathrm{b,c}$ & $137-26-8$ & $\mathrm{~S}$ & Aladdin & $8,5.3,5,4.17,3.47,2.89,2.41$ & moderate \\
\hline 2-Methoxy-4-methylphenol & $93-51-6$ & L & $\mathrm{TCl}$ & $200,133,89,59,40$ & moderate \\
\hline Glyoxal b,c & $107-22-2$ & $\mathrm{~L}$ & Aladdin & $89,80,66.7,55.6,46.3,38.6,32.2$ & moderate \\
\hline trans-Cinnamaldehyde & $14371-10-9$ & $\mathrm{~L}$ & SCR & $6,5,4.17,3.47,2.89$ & moderate \\
\hline Isoeugenol ${ }^{a, b, c}$ & $97-54-1$ & $\mathrm{~L}$ & $\mathrm{TCl}$ & $120,100,83.3,69.4,57.9,48.2,40.2$ & moderate \\
\hline 2-Mercaptobenzothiazole a,b,c & $149-30-4$ & $S$ & SCR & $150,125,104,86.8,72.3,60.3,50.2$ & moderate \\
\hline Cinnamic aldehyde ${ }^{b, c}$ & $104-55-2$ & $\mathrm{~L}$ & Adamas & $7.2,6,5,4.1$ & moderate \\
\hline m-Aminophenol & $591-27-5$ & $S$ & SCR & $150,125,104,87,72,66.7,44.4,29.6$ & moderate \\
\hline Diehtyl maleate & $141-05-9$ & $\mathrm{~L}$ & SCR & $40,26.7,17.8,11.9,9.87$ & moderate \\
\hline Nickel sulfate ${ }^{c}$ & $7786-81-4$ & S & SCR & $120,80,53.3,35.6$ & moderate \\
\hline Resorcinol ${ }^{b, c}$ & $108-46-3$ & $\mathrm{~L}$ & SCR & $500,417,347,289,241,201$ & moderate \\
\hline Nickel chloride ${ }^{a}$ & $7718-54-9$ & $S$ & Aladdin & $100,83.3,69.4,57.9,48.2$ & moderate \\
\hline Citral ${ }^{a, c}$ & $5392-40-5$ & $\mathrm{~L}$ & SCR & $30,25,20.8,17.4,14.5,12.0,10.0,8.4$ & weak \\
\hline Hexyl cinnamic aldehyde ${ }^{a, c}$ & $101-86-0$ & $\mathrm{~L}$ & $\mathrm{TCl}$ & $40,26.7,17.8,11.8$ & weak \\
\hline Eugenol a,b,c & $97-53-0$ & $\mathrm{~L}$ & $\mathrm{TCl}$ & $120,80,53,36$ & weak \\
\hline Phenyl benzoate ${ }^{a, c}$ & $93-99-2$ & $S$ & $\mathrm{TCl}$ & $250,125,62.5,31.2$ & weak \\
\hline Cinnamic alcohol ${ }^{a, b, c}$ & $104-54-1$ & $\mathrm{~L}$ & $\mathrm{TCl}$ & $\begin{array}{l}120,100,83.3,69.4,57.9,48.2,40.2,33.5 \\
27.9\end{array}$ & weak \\
\hline Cyclamen aldehyde & $103-95-7$ & $\mathrm{~L}$ & SCR & $50,41.6,34.7,28.9$ & weak \\
\hline Hydroxycitronellal $^{\mathrm{c}}$ & $107-75-5$ & $\mathrm{~L}$ & SCR & $\begin{array}{l}500,333,222,200,133.3,88.9,59.2,39.5 \\
26.3,17.6,11.7\end{array}$ & weak \\
\hline Imidazolidinyl urea ${ }^{a, c}$ & $39236-46-9$ & $\mathrm{~s}$ & $\mathrm{TCl}$ & $120,100,83.3,69.4,57.9$ & weak \\
\hline Linalool & $78-70-6$ & $\mathrm{~L}$ & $\mathrm{TCl}$ & $1000,667,444,296$ & weak \\
\hline Ethyl acrylate & $140-88-5$ & $\mathrm{~L}$ & SCR & $444,296,197,132$ & weak \\
\hline Methyl methacrylate ${ }^{a}$ & $80-62-6$ & $\mathrm{~L}$ & Aladdin & $\begin{array}{l}5000,4000,3000,2000,1000,833,694 \\
579,500,250,125,62.5\end{array}$ & weak \\
\hline
\end{tabular}




\begin{tabular}{|c|c|c|c|c|c|}
\hline Chemicals & $\begin{array}{l}\text { CAS } \\
\text { number }\end{array}$ & $\begin{array}{l}\text { Physical } \\
\text { form }\end{array}$ & Supplier & Concentrations tested $(\mu \mathrm{g} / \mathrm{mL})$ & $\begin{array}{l}\text { LLNA } \\
\text { potency } \\
\text { category }\end{array}$ \\
\hline \multicolumn{6}{|l|}{18 non-sensitizers } \\
\hline Sodium lauryl sulfate ${ }^{a, b, c}$ & $151-21-3$ & $\mathrm{~S}$ & SCR & $66.7,44.4,29.6$ & FP \\
\hline $\begin{array}{l}\text { Ethylene glycol } \\
\text { dimethacrylate }\end{array}$ & $97-90-5$ & L & $\mathrm{TCl}$ & $150,100,66.7,44.4$ & FP \\
\hline Xylene $^{\mathrm{a}}$ & $1330-20-7$ & $\mathrm{~L}$ & SCR & $1000,667,444,296,198$ & $\mathrm{FP}$ \\
\hline Propyl paraben ${ }^{\mathrm{c}}$ & $94-13-3$ & S & $\begin{array}{l}\text { Sigma- } \\
\text { Aldrich }\end{array}$ & $180,150,125,104.2,86.8,72.3,60.3,50.2$ & \\
\hline Caprylic (octanoic) acid ${ }^{b, c}$ & $124-07-2$ & $\mathrm{~L}$ & SCR & $296,198,132,88$ & \\
\hline Benzalkonium chloride & $8001-54-5$ & $\mathrm{~L}$ & $\mathrm{TCl}$ & $10,5,2.5,1.25,0.625$ & \\
\hline Chlorobenzene ${ }^{a, b, c}$ & $108-90-7$ & $\mathrm{~L}$ & SCR & $5000,4000,3000,2000,1000$ & \\
\hline 4-Aminobenzoic acid & $150-13-0$ & $\mathrm{~S}$ & SCR & $1000,667,444,296$ & \\
\hline Lactic acid a,b,c & $50-21-5$ & $\mathrm{~L}$ & SCR & $1000,833,694,579,482$ & \\
\hline Diethyl phthalate ${ }^{b, c}$ & $86-66-2$ & $\mathrm{~L}$ & SCR & $2000,1000,667,444,296,196$ & \\
\hline Dimethyl isophthalate ${ }^{c}$ & $1459-93-4$ & S & $\mathrm{TCl}$ & $500,333,222,111$ & \\
\hline 2-Hydroxypropyl methacrylate & $27813-02-1$ & $\mathrm{~L}$ & Urchem & $1000,750,500,333,222$ & \\
\hline Glycerol b,c & $56-81-5$ & $\mathrm{~L}$ & SCR & $5000,4000,3000,2000,1000$ & \\
\hline Isopropanol a,c & $67-63-0$ & $\mathrm{~L}$ & SCR & $5000,4000,3000,2000$ & \\
\hline Methyl salicylate ${ }^{a, c}$ & $119-36-8$ & $\mathrm{~L}$ & SCR & $5000,4000,3000,2000,1000,667,444,278$ & \\
\hline Salicylic acid ${ }^{a, b, c}$ & $69-72-7$ & $\mathrm{~S}$ & SCR & 1000 & \\
\hline Sulfanilamide $^{c}$ & $63-74-1$ & $\mathrm{~S}$ & SCR & $1000,667,444,296,198,132$ & \\
\hline Propylene glycol ${ }^{\mathrm{c}}$ & $57-55-6$ & $\mathrm{~L}$ & SCR & $5000,4000,3000,2000,1000$ & \\
\hline
\end{tabular}

L, liquid; S, solid; a Chemicals of the 22 ICCVAM LLNA performance standards reference substances (ICCVAM, 2010); ${ }^{b}$ Chemicals present

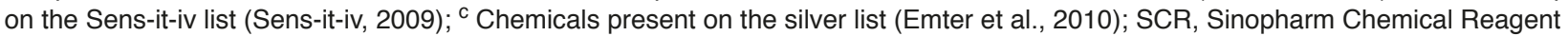
Beijing Co., Ltd, Beijing, China; TCl, Tokyo Chemicals Ind., Tokyo, Japan; Alfa Aesar, USA; Aladdin, Shanghai, China; Urchem, Shanghai, China; Adamas, Belgium; Sigma-Aldrich, USA; the vehicle for nickel sulfate, nickel chloride, and sodium lauryl sulfate was complete RPMI 1640 medium; the vehicle for the other chemicals was dimethyl sulfoxide. FP, false positive in the 22 ICCVAM LLNA performance standards reference substances.

fate was complete RPMI 1640 medium. The vehicle for all other chemicals was DMSO.

The procedure for treatment of the cells was as follows: The Jurkat Clone E6-1 T lymphocytes $\left(1 \times 10^{6}\right.$ cells $/$ well $/ \mathrm{mL}$ in 24-well flat-bottom plate) were incubated with the test chemicals in the given concentrations for $24 \pm 0.5 \mathrm{~h}$. $2.0 \mu \mathrm{g} / \mathrm{mL} \mathrm{2,} \mathrm{4-dini-}$ trochlorobenzene (DNCB) in DMSO was the concurrent positive control in each test run. $2000 \mu \mathrm{g} / \mathrm{mL}(0.2 \%)$ DMSO was the vehicle (negative) control in each test run as well as the final concentration of DMSO in each well containing test chemical.

\section{Flow cytometry analysis}

After exposure to the chemicals, cells were transferred from the 24-well plate into a $5 \mathrm{~mL}$ tube (\#352052, BD Falcon) and washed twice with $1.5 \mathrm{~mL}$ staining buffer (phosphate-buffered saline (PBS) solution containing $0.1 \%(\mathrm{w} / \mathrm{v})$ bovine serum albumin). Then cells were blocked with $600 \mu \mathrm{L}$ blocking solution (staining buffer containing $0.01 \%(\mathrm{w} / \mathrm{v})$ globulin (Cohn fraction II, III, human: SIGMA, \#G2388-10G)) and incubated at $4{ }^{\circ} \mathrm{C}$ for $15 \mathrm{~min}$. After blocking, two $90 \mu \mathrm{L}$ aliquots of the cells were transferred into a 96-well round-bottom plate or $180 \mu \mathrm{L}$ into a small tube. After centrifugation, cells were stained with $25 \mu \mathrm{L}$ (or $50 \mu \mathrm{L}$ for small tube) of FITC (fluorescein isothiocyanate)-labelled mouse anti-human CD69 antibody (BD-PharMingen, \#555530; Clone: FN50) or FITC-labelled mouse IgG1 (CD69 isotype antibody) (BD-PharMingen, \#555748; Clone: MOPC-21) at $4^{\circ} \mathrm{C}$ for $30 \mathrm{~min}$. The two antibodies were diluted 3:25 (v/v) in staining buffer. After washing three times with $150 \mu \mathrm{L}$ staining buffer, dead cells in the samples were stained with $25 \mu \mathrm{L}$ (or $50 \mu \mathrm{L}$ for small tube) 7-aminoactinomycin D (7-AAD) (Abcam, \#ab228563; diluted 1:25 (v/v) with staining buffer) at room temperature for $5 \mathrm{~min}$. Then $150 \mu \mathrm{L}$ (or $300 \mu \mathrm{L}$ for small tube) staining buffer was added to each well (or each tube) to re-suspend the cells. Expression levels of CD69 and cell viability were analyzed using flow cytometry (Accuri C6, 
Tab. 2: Predictive performances for different positive criteria

\begin{tabular}{|l|l|l|l|}
\hline $\begin{array}{l}\text { Positive } \\
\text { criteria } \\
\text { (CD69 RFI) }\end{array}$ & Sensitivity & Specificity & Accuracy \\
\hline 1.3 & $88.2 \%(30 / 34)$ & $61.1 \%(11 / 18)$ & $78.8 \%(42 / 52)$ \\
\hline 1.4 & $85.3 \%(29 / 34)$ & $72.2 \%(13 / 18)$ & $80.8 \%(42 / 52)$ \\
\hline 1.5 & $79.4 \%(27 / 34)$ & $88.9 \%(16 / 18)$ & $82.7 \%(43 / 52)$ \\
\hline 1.6 & $79.4 \%(27 / 34)$ & $88.9 \%(16 / 18)$ & $82.7 \%(43 / 52)$ \\
\hline 1.7 & $79.4 \%(27 / 34)$ & $88.9 \%(16 / 18)$ & $82.7 \%(43 / 52)$ \\
\hline 1.8 & $76.5 \%(26 / 34)$ & $88.9 \%(16 / 18)$ & $80.8 \%(42 / 52)$ \\
\hline 1.9 & $76.5 \%(26 / 34)$ & $88.9 \%(16 / 18)$ & $80.8 \%(42 / 52)$ \\
\hline 2.0 & $76.5 \%(26 / 34)$ & $88.9 \%(16 / 18)$ & $80.8 \%(42 / 52)$ \\
\hline 2.1 & $67.6 \%(23 / 34)$ & $88.9 \%(16 / 18)$ & $75.0 \%(39 / 52)$ \\
\hline 2.2 & $58.8 \%(20 / 34)$ & $100 \%(18 / 18)$ & $73.1 \%(38 / 52)$ \\
\hline Altgether 52 reference substances 1 (uding 34
\end{tabular}

Altogether 52 reference substances including 34 skin sensitizers and 18 non-sensitizers were tested in this test model (see Tab. 1). A substance was judged as a sensitizer (i.e., positive response) when its maximum CD69 RFI value (see Tab. 3 ) exceeded the indicated positive criteria. Sensitivity: The proportion of skin sensitizers that are correctly identified as positive according to the corresponding positive criteria. Specificity: The proportion of nonsensitizers that are correctly identified as negative according to the corresponding positive criteria. Accuracy: the proportion of correct outcomes according to the corresponding positive criteria.
BD Biosciences) in the acquisition channels FL-1 and FL-3, respectively. A total of 10,000 living cells (7-AAD negative) were acquired. The geometric mean fluorescence intensity (MFI) was recorded and the relative fluorescence intensity (RFI) value of CD69 expression (CD69 RFI) at each concentration of test substance was calculated according to the following equation:

$$
\text { CD69 RFI }=\frac{(\text { MFI of chemical treated cells }- \text { MFI of chemical }}{\text { treated isotype control) }}
$$

\section{Results}

\subsection{Positive criteria}

When cell viability was less than $50 \%$, the RFI was not calculated as intracellular interfering structures might be labeled due to cell membrane destruction, which could interfere with fluorescent measurement. Initially, the predictive performance at different cut-off values for CD69 RFI was assessed (Tab. 2). The best prediction accuracy $(82.7 \%)$ was found when the cut-off was between 1.5 and 1.7. To ensure optimal sensitivity of the test, the lower cut-off border of 1.5 was selected as the prediction rule. Therefore, the criterion to predict CD69 expression at a specific concentration of test chemical as a positive response was set as CD69 RFI $\geq 1.5$ at cell viability $\geq 50 \%$.

Tab. 3: Results of CD69 expression induced by the 52 substances tested in our study

\begin{tabular}{|l|l|l|l|}
\hline Substances & CD69 prediction (1.5-fold) & Maximum CD69 RFI & Positive runs in total runs \\
\hline 34 sensitizers & & & \\
\hline Oxazolone & - & 1.22 & $0 / 2$ \\
\hline 5-Chloro-2-methyl-4-isothiazolin-3-one ${ }^{a}$ & - & 1.49 & $0 / 3$ \\
\hline p-Benzoquinone & + & 2.35 & $3 / 3$ \\
\hline 2,4-Dinitrochlorobenzene ${ }^{\text {a }}$ & + & 3.51 & $25 / 25$ \\
\hline 4-Nitrobenzyl bromide & + & 4.01 & $2 / 2$ \\
\hline Benzo[a]pyrene & + & 6.24 & $2 / 2$ \\
\hline Glutaraldehyde & + & 3.26 & $2 / 2$ \\
\hline 4-Phenylenediamine ${ }^{a}$ & + & 3.24 & $2 / 2$ \\
\hline Formaldehyde & + & 2.22 & $3 / 3$ \\
\hline Cobalt chloride ${ }^{a}$ & + & 5.87 & $3 / 3$ \\
\hline 4-Methylaminophenol sulfate & + & 2.37 & $2 / 2$ \\
\hline Tetramethylthiuram disulfide & + & 3.23 & $2 / 2$ \\
\hline 2-Methoxy-4-methylphenol & + & 2.07 & $2 / 2$ \\
\hline Glyoxal & + & 8.63 & $2 / 2$ \\
\hline trans-Cinnamaldehyde & + & 2.33 & $3 / 3$ \\
\hline Isoeugenol ${ }^{a}$ & - & 1.39 & $0 / 3$ \\
\hline
\end{tabular}




\begin{tabular}{|c|c|c|c|}
\hline Substances & CD69 prediction (1.5-fold) & Maximum CD69 RFI & Positive runs in total runs \\
\hline 2-Mercaptobenzothiazole ${ }^{a}$ & + & 2.04 & $2 / 2$ \\
\hline Cinnamic aldehyde & - & 1.09 & $1 / 3$ \\
\hline m-Aminophenol & + & 4.84 & $2 / 2$ \\
\hline Diehtyl maleate & + & 2.12 & $2 / 2$ \\
\hline Nickel sulfate & + & 3.87 & $2 / 2$ \\
\hline Resorcinol & + & 3.20 & $2 / 2$ \\
\hline Nickel chloride ${ }^{a}$ & + & 2.15 & $3 / 3$ \\
\hline Citral $^{a}$ & - & 1.09 & $1 / 3$ \\
\hline Hexyl cinnamic aldehyde $^{a}$ & + & 3.34 & $2 / 2$ \\
\hline Eugenol $^{\text {a }}$ & + & 2.36 & $2 / 2$ \\
\hline Phenyl benzoate $^{a}$ & + & 2.10 & $2 / 2$ \\
\hline Cinnamic alcohol ${ }^{a}$ & - & 1.24 & $0 / 2$ \\
\hline Cyclamen aldehyde & + & 1.80 & $2 / 2$ \\
\hline Hydroxycitronellal & + & 17.29 & $3 / 3$ \\
\hline Imidazolidinyl urea $^{a}$ & + & 2.04 & $2 / 2$ \\
\hline Linalool & + & 2.99 & $2 / 2$ \\
\hline Ethyl acrylate & + & 3.25 & $2 / 2$ \\
\hline Methyl methacrylate a & - & 1.49 & $0 / 3$ \\
\hline \multicolumn{4}{|l|}{18 non-sensitizers } \\
\hline Sodium lauryl sulfate ${ }^{a}$ & + & 2.18 & $2 / 2$ \\
\hline Ethylene glycol dimethacrylate ${ }^{a}$ & - & 1.41 & $0 / 3$ \\
\hline Xylene $^{a}$ & - & 1.31 & $0 / 2$ \\
\hline Propylparaben & - & 1.38 & $0 / 2$ \\
\hline Caprylic (octanoic) acid & - & 1.46 & $0 / 2$ \\
\hline Benzalkonium chloride & - & 1.06 & $0 / 2$ \\
\hline Chlorobenzene $^{a}$ & - & 1.25 & $0 / 2$ \\
\hline 4-Aminobenzoic acid & - & 1.01 & $0 / 2$ \\
\hline Lactic acid $^{\mathrm{a}}$ & - & 1.25 & $1 / 3$ \\
\hline Diethyl phthalate & - & 1.29 & $0 / 3$ \\
\hline Dimethyl isophthalate & - & 0.61 & $0 / 2$ \\
\hline 2-Hydroxypropyl methacrylate & - & 1.22 & $1 / 3$ \\
\hline Glycerol & - & 1.15 & $0 / 3$ \\
\hline Isopropanol $^{a}$ & - & 1.49 & $0 / 5$ \\
\hline Methyl salicylate $^{a}$ & - & 1.24 & $0 / 3$ \\
\hline Salicylic acid ${ }^{a}$ & + & 2.19 & $2 / 2$ \\
\hline Sulfanilamide & - & 1.07 & $0 / 2$ \\
\hline Propylene glycol & - & 1.29 & $0 / 2$ \\
\hline
\end{tabular}

Concentrations tested for each substance are shown in Table 1. The relative fluorescence intensity of CD69 (CD69 RFI) $\geq 1.5$ was the criterion to identify the response as positive. +, positive response; -, negative response. For chemicals that were predicted as positive, the maximum CD69 RFI was the maximum CD69 RFI value among all concentrations tested and among all runs tested for the chemical. For chemicals predicted as negative, the maximum CD69 RFI value was the maximum CD69 RFI value among the runs with negative prediction. a Chemicals of the 22 ICCVAM LLNA performance standards reference substances (ICCVAM, 2010). 


\subsection{Prediction standard}

The prediction standard for the test substances was defined as the following: If a positive response can be reproduced in 2 of 3 independent runs, the prediction of the chemical is considered positive. Otherwise the prediction is considered negative. Negative results are acceptable if the highest concentration tested is high enough to exhibit cell viability $<75 \%$, or if the highest concentration tested is $1000 \mu \mathrm{g} / \mathrm{mL}$ in DMSO or the test chemical's highest soluble concentration. If consistent positive or negative responses are obtained in the first two independent runs, the third run is not needed. The prediction results for each test substance are shown in Table 3.

In addition, to accept a negative result for a substance in our test, the results of the concurrent positive control must be a positive response. In this study, the concurrent positive control in each independent run was $2 \mu \mathrm{g} / \mathrm{mL}$ DNCB. It was tested in 25 independent runs altogether. DNCB induced a positive response (i.e., the CD69 RFI $\geq 1.5$ ) in all 25 runs (Tab. 4). The means of all CD69 RFI values and all cell viability values of DNCB were $2.66 \pm 0.47$ (mean $\pm \mathrm{SD}$ ) and $81.1 \% \pm 10.6 \%$ (mean $\pm \mathrm{SD}$ ), respectively. The coefficient of variation (CV) was calculated to indicate the repeatability of the assay by dividing the standard deviation by the mean. The CVs for CD69 RFI and cell viability of DNCB were $17.7 \%$ and $13.1 \%$, respectively. These results for the positive control on the one hand demonstrate the inhouse reproducibility of our test to identify skin sensitizers, and on the other hand indicate the magnitude of the response in the positive control group and its variation range. These data supply a reference for considering the appropriateness of the result of the positive control.

\subsection{The highest CD69 RFI value for each substance}

For chemicals that were predicted as positive in our test, the highest CD69 RFI value induced by a chemical was the highest CD69 RFI value among all concentrations tested and among all runs tested for the chemical (Tab. 3). It could indicate the magnitude of CD69 expression elicited by the substance. For chemicals predicted as negative, the highest CD69 RFI value induced by a chemical was the highest CD69 RFI value among the runs with negative prediction (Tab. 3). Based on these highest CD69 RFI values, 27 sensitizers were correctly predicted as positive and 16 non-sensitizers were correctly predicted as negative; 7 sensitizers were falsely predicted as negative and 2 non-sensitizers were falsely predicted as positive (Tab. 3).

Among the highest RFI values for the 27 sensitizers judged as positive, the highest (17.29) was induced by the weak sensitizer hydroxycitronellal (Tab. 3). Thus, the magnitude of CD69 expression induced by the sensitizers did not appear to correlate with their skin sensitization potency classification shown in Table 1.

\subsection{The sensitivity, specificity and accuracy of our test to discriminate skin sensitizers from non-sensitizers}

The chemicals tested were identified as positive or negative based on the positive criteria and the prediction standard for CD69 expression described above.

Of the 34 sensitizers tested, 27 sensitizers were correctly identified as positive, 7 sensitizers were falsely identified as negative
Tab. 4: Results of $2 \mu \mathrm{g} / \mathrm{mL} 2$, 4-dinitrochlorobenzene (the concurrent positive control) repeatedly tested in 25 independent runs

\begin{tabular}{|c|c|c|c|}
\hline $\begin{array}{l}\text { Test } \\
\text { repeats }\end{array}$ & $\begin{array}{l}\text { Cell viability } \\
(\%)\end{array}$ & CD69 RFI & $\begin{array}{l}\text { Identified } \\
\text { (1.5-fold increase) }\end{array}$ \\
\hline 1 & 95.3 & 3.51 & + \\
\hline 2 & 94.1 & 3.27 & + \\
\hline 3 & 87.2 & 2.68 & + \\
\hline 4 & 93.6 & 2.96 & + \\
\hline 5 & 97.2 & 2.82 & + \\
\hline 6 & 95.2 & 3.51 & + \\
\hline 7 & 96.1 & 2.44 & + \\
\hline 8 & 92.6 & 2.56 & + \\
\hline 9 & 92.5 & 2.24 & + \\
\hline 10 & 73.2 & 3.03 & + \\
\hline 11 & 75.2 & 2.49 & + \\
\hline 12 & 80.5 & 2.27 & + \\
\hline 13 & 73.6 & 2.00 & + \\
\hline 14 & 75.4 & 2.53 & + \\
\hline 15 & 78.8 & 3.31 & + \\
\hline 16 & 68.9 & 3.11 & + \\
\hline 17 & 65.2 & 2.64 & + \\
\hline 18 & 71.7 & 3.19 & + \\
\hline 19 & 69.2 & 1.90 & + \\
\hline 20 & 74.3 & 2.68 & + \\
\hline 21 & 82.6 & 2.14 & + \\
\hline 22 & 68.2 & 2.30 & + \\
\hline 23 & 82.2 & 2.51 & + \\
\hline 24 & 73.7 & 2.25 & + \\
\hline 25 & 71.0 & 2.10 & + \\
\hline
\end{tabular}

(Tab. 3). Thus, the sensitivity of the test was $79.4 \%$ (27/34). Of the 7 false negatives, oxazolone and 5-chloro-2-methyl-4-isothiazolin-3-one are extreme sensitizers; isoeugenol (prehapten) and cinnamic aldehyde (prehapten) are moderate sensitizers; cinnamic alcohol (prohapten), citral, and methyl methacrylate are weak sensitizers.

Of the 18 non-sensitizers, 16 non-sensitizers were correctly identified as negative, 2 non-sensitizers were falsely identified as positive. Thus, the specificity of the test was 88.9\% (16/18) (Tab. 3 ). The two chemicals that were false-positive were sodium lauryl sulfate and salicylic acid (Tab. 3).

As stated above, a total of 52 substances including 34 sensitizers and 18 non-sensitizers were tested in this study, of which 27 sensitizers were correctly identified as positive and 16 non-sensitizers 
Tab. 5: Comparison of the prediction results of our study with those of the OECD assays for the 52 substances

\begin{tabular}{|c|c|c|c|c|c|c|}
\hline Substances & Our test & DPRA & KeratinoSens $^{\mathrm{TM}}$ & h-CLAT & U-SENS ${ }^{\mathrm{TM}}$ & IL-8 Luc \\
\hline \multicolumn{7}{|l|}{34 sensitizers } \\
\hline Oxazolone & - & + & + & + & + & + \\
\hline $\begin{array}{l}\text { 5-Chloro-2-methyl-4- } \\
\text { isothiazolin-3-one }\end{array}$ & - & + & + & + & + & NA \\
\hline p-Benzoquinone & + & + & + & + & + & + \\
\hline 2,4-Dinitrochlorobenzene & + & + & + & + & + & + \\
\hline 4-Nitrobenzyl bromide & + & + & + & + & + & + \\
\hline Benzo[a]pyrene & + & + & + & + & + & NA \\
\hline Glutaraldehyde & + & + & + & + & + & + \\
\hline 4-Phenylenediamine & + & + & + & + & + & + \\
\hline Formaldehyde & + & + & + & + & + & + \\
\hline Cobalt chloride & + & + & + & + & NA & + \\
\hline 4-Methylaminophenol sulfate & + & + & + & + & + & NA \\
\hline Tetramethylthiuram disulfide & + & + & + & + & + & + \\
\hline 2-Methoxy-4-methylphenol & + & - & - & + & + & + \\
\hline Glyoxal & + & + & + & + & + & + \\
\hline trans-Cinnamaldehyde & + & NA & NA & NA & NA & NA \\
\hline Isoeugenol & - & + & + & - & + & + \\
\hline 2-Mercaptobenzothiazole & + & + & + & + & + & + \\
\hline Cinnamic aldehyde & - & + & + & + & + & + \\
\hline m-Aminophenol & + & - & - & + & + & + \\
\hline Diethyl maleate & + & + & + & + & + & - \\
\hline Nickel sulfate & + & + & + & + & + & + \\
\hline Resorcinol & + & - & - & + & + & + \\
\hline Nickel chloride & + & - & + & + & NA & + \\
\hline Citral & - & + & + & + & + & + \\
\hline Hexyl cinnamic aldehyde & + & - & + & - & + & + \\
\hline Eugenol & + & + & - & + & + & + \\
\hline Phenyl benzoate & + & + & - & + & + & + \\
\hline Cinnamic alcohol & - & + & + & + & + & + \\
\hline Cyclamen aldehyde & + & + & NA & - & + & + \\
\hline Hydroxycitronellal & + & + & + & + & + & + \\
\hline Imidazolidinyl urea & + & + & + & + & + & + \\
\hline Linalool & + & - & - & + & + & + \\
\hline Ethyl acrylate & + & + & + & - & + & NA \\
\hline Methyl methacrylate & - & + & + & + & + & - \\
\hline \multicolumn{7}{|l|}{18 non-sensitizers } \\
\hline Sodium lauryl sulfate & + & - & - & - & + & + \\
\hline
\end{tabular}




\begin{tabular}{|c|c|c|c|c|c|c|}
\hline Substances & Our test & DPRA & KeratinoSens $^{\mathrm{TM}}$ & h-CLAT & U-SENS ${ }^{\text {TM }}$ & IL-8 Luc \\
\hline Ethylene glycol dimethacrylate & - & + & + & + & + & - \\
\hline Xylene & - & - & - & + & - & - \\
\hline Propyl paraben & - & - & + & + & + & - \\
\hline Caprylic (octanoic) acid & - & - & - & + & + & - \\
\hline Benzalkonium chloride & - & - & - & - & + & + \\
\hline Chlorobenzene & - & - & - & + & - & - \\
\hline 4-Aminobenzoic acid & - & - & - & - & - & - \\
\hline Lactic acid & - & - & - & - & - & - \\
\hline Diethyl phthalate & - & - & - & + & + & + \\
\hline Dimethyl isophthalate & - & NA & + & NA & NA & - \\
\hline 2-Hydroxypropyl methacrylate & - & + & NA & - & NA & - \\
\hline Glycerol & - & - & - & - & - & - \\
\hline Isopropanol & - & - & - & - & - & - \\
\hline Methyl salicylate & - & - & - & - & - & - \\
\hline Salicylic acid & + & + & - & + & - & - \\
\hline Sulfanilamide & - & - & - & - & - & - \\
\hline Propylene glycol & - & - & - & - & - & - \\
\hline Sensitivity ${ }^{a}$ & $79.4 \%(27 / 34)$ & $81.8 \%(27 / 33)$ & $81.2 \%(26 / 32)$ & $87.9 \%(29 / 33)$ & $100 \%{ }^{*}(31 / 31)$ & $93.1 \%(27 / 29)$ \\
\hline Specificity ${ }^{a}$ & $88.9 \%(16 / 18)$ & $82.4 \%(14 / 17)$ & $82.4 \%(14 / 17)$ & $58.8 \%(10 / 17)$ & $62.5 \%(10 / 16)$ & $83.3 \%(15 / 18)$ \\
\hline Accuracy ${ }^{a}$ & $82.7 \%(43 / 52)$ & $82 \%(41 / 50)$ & $81.6 \%(40 / 49)$ & $78 \%(39 / 50)$ & $87.2 \%(41 / 47)$ & $89.4 \%(42 / 47)$ \\
\hline Sensitivity ${ }^{b}$ & $78.8 \%(26 / 33)$ & $81.8 \%(27 / 33)$ & & & & \\
\hline Specificity ${ }^{b}$ & $88.2 \%(15 / 17)$ & $82.4 \%(14 / 17)$ & & & & \\
\hline Accuracy ${ }^{b}$ & $82 \%(41 / 50)$ & $82 \%(41 / 50)$ & & & & \\
\hline Sensitivity ${ }^{c}$ & $78.1 \%(25 / 32)$ & & $81.2 \%(26 / 32)$ & & & \\
\hline Specificity ${ }^{C}$ & $88.2 \%(15 / 17)$ & & $82.4 \%(14 / 17)$ & & & \\
\hline Accuracy ${ }^{c}$ & $81.6 \%(40 / 49)$ & & $81.6 \%(40 / 49)$ & & & \\
\hline Sensitivity ${ }^{d}$ & $78.8 \%(26 / 33)$ & & & $87.9 \%(29 / 33)$ & & \\
\hline Specificity ${ }^{d}$ & $88.2 \%(15 / 17)$ & & & $58.8 \%(10 / 17)$ & & \\
\hline Accuracy ${ }^{d}$ & $82 \%(41 / 50)$ & & & $78 \%(39 / 50)$ & & \\
\hline Sensitivity ${ }^{e}$ & $77.4 \%(24 / 31)$ & & & & $100 \%{ }^{*}(31 / 31)$ & \\
\hline Specificity ${ }^{e}$ & $87.5 \%(14 / 16)$ & & & & $62.5 \%(10 / 16)$ & \\
\hline Accuracy ${ }^{e}$ & $80.8 \%(38 / 47)$ & & & & $87.2 \%(41 / 47)$ & \\
\hline Sensitivity ${ }^{\dagger}$ & $79.3 \%(23 / 29)$ & & & & & $93.1 \%(27 / 29)$ \\
\hline Specificity ${ }^{f}$ & $88.9 \%(16 / 18)$ & & & & & $83.3 \%(15 / 18)$ \\
\hline Accuracy ${ }^{f}$ & $83.0 \%(39 / 47)$ & & & & & $89.4 \%(42 / 47)$ \\
\hline
\end{tabular}

+ , positive response; -, negative response; NA, not available; ${ }^{*}, p<0.05$. Chi-square test was used to compare the differences of the sensitivity, specificity and accuracy of this test model with that of the DPRA, the KeratinoSens, the h-CLAT, the U-SENS, and the IL-8 Luc ${ }^{a}$ based on the chemicals with available data in each assay or based on only chemicals with available data in the ${ }^{b}$ DPRA, ${ }^{c}$ KeratinoSens, ${ }^{d} \mathrm{~h}-\mathrm{CLAT}$, ${ }^{\mathrm{e}} \mathrm{U}-\mathrm{SENS}$, or ${ }^{f}$ IL-8 Luc. Software of Statistical Product and Service Solutions 17.0 (SPSS 17.0) was used for the comparisons. 
were correctly identified as negative (Tab. 3). Thus, the accuracy of our test based on the 52 substances was $82.7 \%((27+16) / 52)$.

All 22 substances of the LLNA performance standards reference substances (ICCVAM, 2010) were tested in this study. They included 14 sensitizers and 8 non-sensitizers (Tab. 3). Nine out of the 14 sensitizers were correctly identified as positive, and 6 out of the 8 non-sensitizers were correctly identified as negative (Tab. 3). Thus, the sensitivity, specificity and accuracy of our test based on only these 22 substances was $64.3 \%(9 / 14), 75 \%(6 / 8)$, and $68.2((9+6) / 22)$, respectively. These values were lower than the overall sensitivity (79.4\%), specificity (88.9\%) and accuracy $(82.7 \%)$ based on the 52 substances.

\subsection{Comparison of the sensitivity, specificity and accuracy of our test to identify skin sensitizers with the DPRA, the KeratinoSens ${ }^{\mathrm{TM}}$, the h-CLAT, the U-SENS ${ }^{\mathrm{TM}}$ and the IL-8 Luc}

The direct peptide reactivity assay (DPRA) (OECD, 2015a), the in vitro skin sensitisation: ARE-Nrf2 luciferase test method (KeratinoSens $\left.{ }^{\mathrm{TM}}\right)(\mathrm{OECD}, 2015 \mathrm{~b})$, the human cell line activa-

Tab. 6: Pearson linear correlation analysis for the dose-effect relationship of CD69 RFI and cell viability with the concentrations tested for the 27 sensitizers showing positive response

\begin{tabular}{|c|c|c|c|c|}
\hline \multirow[t]{2}{*}{ Substances } & \multicolumn{2}{|c|}{$\begin{array}{l}\text { Correlation of CD69 RFI with } \\
\text { concentrations tested }\end{array}$} & \multicolumn{2}{|c|}{$\begin{array}{l}\text { Correlation of cell viability with } \\
\text { concentrations tested }\end{array}$} \\
\hline & $\mathbf{R}$ & $p$ & $\mathbf{R}$ & $p$ \\
\hline p-Benzoquinone & 0.975 & 0.002 & -0.950 & 0.007 \\
\hline 2,4-Dinitrochlorobenzene & 0.951 & 0.024 & -0.900 & 0.05 \\
\hline 4-Nitrobenzyl bromide & 0.879 & 0.01 & -0.428 & 0.199 \\
\hline Glutaraldehyde & 0.948 & 0.026 & -0.931 & 0.034 \\
\hline 4-Phenylenediamine & 0.774 & 0.062 & -0.719 & 0.085 \\
\hline Formaldehyde & 0.891 & 0.009 & -0.782 & 0.033 \\
\hline Cobalt chloride & 0.250 & 0.316 & -0.973 & 0.001 \\
\hline 4-Methylaminophenol sulfate & 0.992 & 0.004 & -0.868 & 0.066 \\
\hline Benzo[a]pyrene & 0.845 & 0.004 & -0.641 & 0.043 \\
\hline Tetramethylthiuram disulfide & 0.990 & 0.001 & -0.913 & 0.015 \\
\hline 2-Methoxy-4-methylphenol & 0.793 & 0.055 & -0.850 & 0.034 \\
\hline Glyoxal & 0.938 & 0.003 & -0.961 & 0.001 \\
\hline trans-Cinnamaldehyde & 0.994 & 0.000 & -0.961 & 0.005 \\
\hline 2-Mercaptobenzothiazole & 0.908 & 0.002 & -0.882 & 0.004 \\
\hline m-Aminophenol & 0.517 & 0.186 & -0.938 & 0.009 \\
\hline Diehtyl maleate & 0.967 & 0.004 & -0.990 & 0.001 \\
\hline Nickel sulfate & 0.717 & 0.141 & -0.970 & 0.015 \\
\hline Resorcinol & 0.044 & 0.467 & -0.783 & 0.033 \\
\hline Nickel chloride & 0.834 & 0.04 & -0.990 & 0.001 \\
\hline Hexyl cinnamic aldehyde & 0.960 & 0.02 & -0.989 & 0.005 \\
\hline Eugenol & 0.564 & 0.218 & -0.986 & 0.007 \\
\hline Phenyl benzoate & 0.605 & 0.198 & 0.321 & 0.339 \\
\hline Cyclamen aldehyde & 0.996 & 0.002 & -0.942 & 0.029 \\
\hline Hydroxycitronellal & 0.940 & 0.000 & -0.899 & 0.000 \\
\hline Imidazolidinyl urea & 0.949 & 0.026 & -0.958 & 0.021 \\
\hline Linalool & 0.983 & 0.008 & -0.108 & 0.446 \\
\hline Ethyl acrylate & 0.945 & 0.028 & -0.987 & 0.006 \\
\hline
\end{tabular}

Pearson linear correlation analysis was conducted to analyze the magnitude of the linear correlation of the dose-effect relationship shown in Figure 1; R, Pearson linear correlation coefficient; $p$, statistical significance for the linear correlation; Software of Statistical Product and Service Solutions 17.0 (SPSS 17.0) was used for the analysis. 


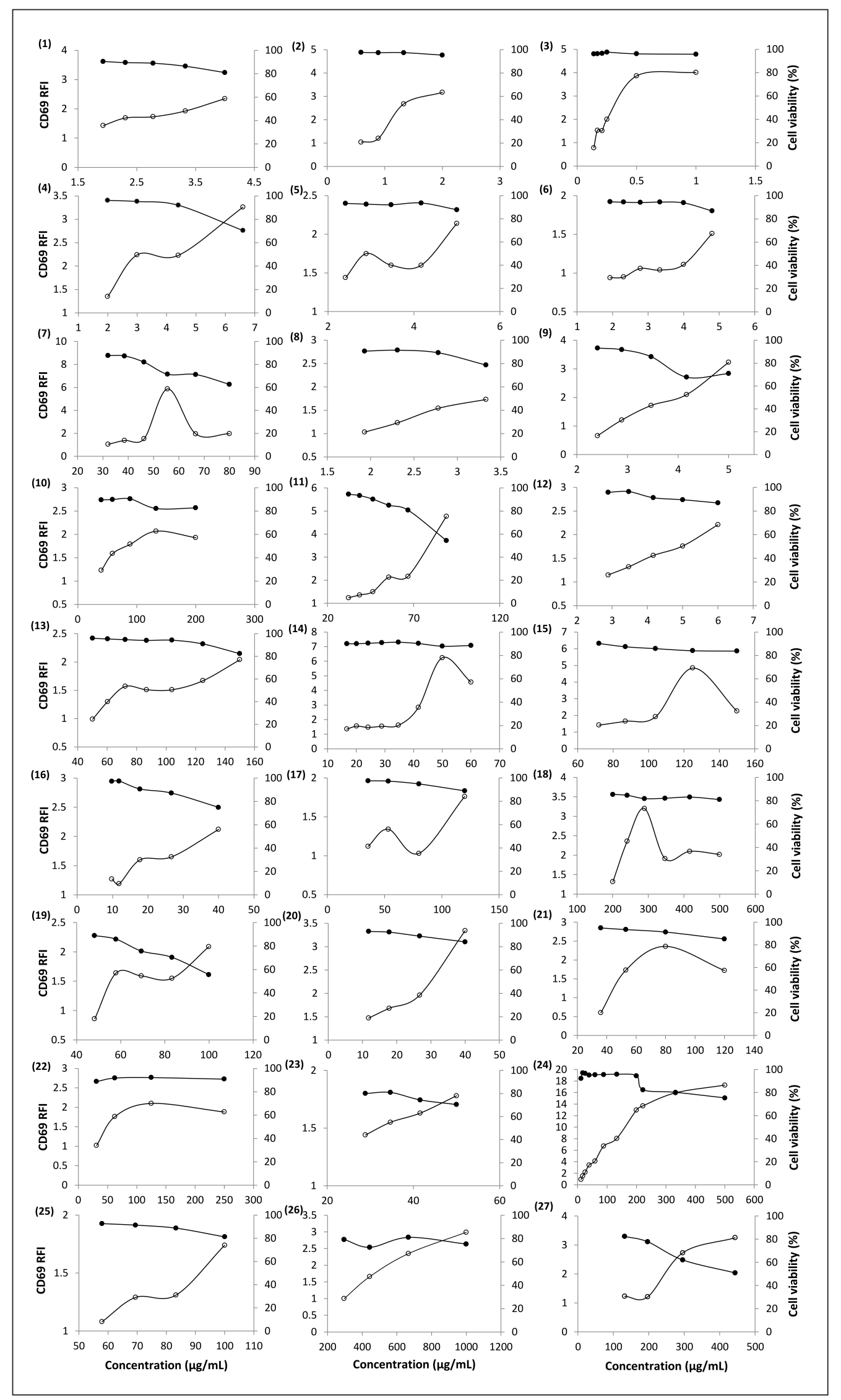

Fig. 1: Dose-effect relationship of CD69 RFI (open circles "o") and cell viability (filled circles “॰”) for the 27 skin sensitizers showing a positive response (1) p-benzoquinone;

(2) 2,4-dinitrochlorobenzene;

(3) 4-nitrobenzyl bromide;

(4) glutaraldehyde;

(5) 4-phenylenediamine;

(6) formaldehyde;

(7) cobalt chloride;

(8) 4-methylaminophenol sulfate;

(9) tetramethylthiuram disulfide;

(10) 2-methoxy-

4-methylphenol;

(11) glyoxal;

(12) trans-cinnamaldehyde;

(13) 2-mercaptobenzothiazole;

(14) benzo[a]pyrene;

(15) m-aminophenol;

(16) diehtyl maleate;

(17) nickel sulfate;

(18) resorcinol;

(19) nickel chloride;

(20) hexyl cinnamic aldehyde;

(21) eugenol;

(22) phenyl benzoate;

(23) cyclamen aldehyde;

(24) hydroxycitronellal;

(25) imidazolidinyl urea;

(26) linalool;

(27) ethyl acrylate. 
tion test (h-CLAT) (OECD, 2018); the U937 cell line activation test (U-SENSTM) (OECD, 2018), and the interleukin-8 reporter gene assay (IL-8 Luc) (OECD, 2018) are the in vitro assays for skin sensitization that have been formally adopted by the OECD. They model the first three of the four KEs, while the assay described here models the fourth AOP KE for skin sensitization. The sensitivity, specificity and accuracy of this assay was compared with that of the DPRA, the KeratinoSens ${ }^{\mathrm{TM}}$, the h-CLAT, the U-SENSTM and the IL-8 Luc, respectively, to assess the comparative performance of our test.

For the comparison, the reported data on the prediction results of the 52 chemicals in the DPRA (Nukada et al., 2013; Urbisch et al., 2016; Hoffmann et al., 2018; Cho et al., 2020), the KeratinoSens (Emter, 2010; Urbisch et al., 2016; Hoffmann et al., 2018; Cho et al., 2020), the h-CLAT (Nukada et al., 2012, 2013; Hoffmann et al., 2018; Cho et al., 2020), the U-SENS (Piroird et al., 2015; Hoffmann et al., 2018), and the IL-8 Luc (Takahashi et al., 2011; Kimura et al., 2015) were used (Tab. 5). The sensitivitya,

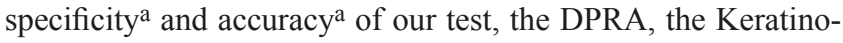
Sens, the h-CLAT, the U-SENS, and the IL-8 Luc were calculated based on the chemicals with available data in each assay (Tab. 5). Next, the sensitivity ${ }^{\mathrm{b}}$, specificity $^{\mathrm{b}}$ and accuracy $^{\mathrm{b}}$ of our test were calculated based on only the chemicals with available data in the DPRA (33 sensitizers and 17 non-sensitizers). Also, the sensitivity ${ }^{\mathrm{c}}$, specificity ${ }^{\mathrm{c}}$ and accuracy $^{\mathrm{c}}$ of our test were calculated based on the only the chemicals with available data in the KeratinoSens ( 32 sensitizers and 17 non-sensitizers). Then, the sensitivity ${ }^{d}$, specificity ${ }^{d}$ and accuracy ${ }^{d}$ of our test were calculated based on only chemicals with available data in the h-CLAT (33 sensitizers and 17 non-sensitizers). Further, the sensitivitye, specificity and accuracy ${ }^{\mathrm{e}}$ of our test were calculated based on only chemicals with available data in the U-SENS (31 sensitizers and 16 non-sensitizers). Finally, the sensitivity ${ }^{\mathrm{f}}$, specificity ${ }^{f}$ and accuracy ${ }^{f}$ of our test were calculated based on only the chemicals with available data in the IL- 8 Luc ( 29 sensitizers and 18 non-sensitizers). The chi-square test was used for the comparisons.

There were no statistically significant differences for any of the comparisons except for the difference in sensitivity between our assay and the U-SENS ${ }^{\mathrm{TM}}(p<0.05)$ (Tab. 5). Although not statistically significant, our test showed a slightly lower sensitivity and a higher specificity than the 5 OECD assays (Tab. 5).

\subsection{The dose-effect relationship of CD69 expression and cell viability}

For the 27 sensitizers showing a positive response in our test, the dose-effect relationships of CD69 expression and cell viability are shown in Figure 1. The panels show that an increase in CD69 RFI with increasing concentrations of test chemical was associated with a decrease in cell viability. Pearson linear correlation coefficient $(\mathrm{R})$ values with $p$-values show the magnitude of the linear correlation (Tab. 6).

Of the 27 R-values for the relationship between CD69 RFI and the concentrations tested, $15 \mathrm{R}$-values were greater than 0.9 , 19 were greater than 0.8 , and only 2 were smaller than 0.5 (Tab. $6)$. Of the $27 p$-values, $13 p$-values were smaller than 0.01 and
19 were smaller than 0.05 (Tab. 6). Thus, for most sensitizers, the increase in CD69 expression had a statistically significant correlation with the concentrations tested.

Of the $27 \mathrm{R}$-values for the relationship between cell viability and the concentrations tested, $16 \mathrm{R}$-values were greater than $0.9,20$ were greater than 0.8 , and only 3 were smaller than 0.5 (Tab. 6). Of the $27 p$-values, 12 were smaller than 0.01 and 22 were smaller than 0.05 (Tab. 6). Thus, for most sensitizers, the decrease in cell viability had statistically significant correlation with the concentrations tested.

\subsection{The EC1.5 value}

For the 27 sensitizers showing a positive result, the EC1.5 values, i.e., the concentration at which a test chemical induced a CD69 RFI of 1.5 , were calculated according to the following equation to assess their skin sensitizing potency. The equation is based on the same rule as for the calculation of LLNA EC3.

$\mathrm{EC} 1.5=\mathrm{B}_{\text {conc. }}+\left[\left(1.5-\mathrm{B}_{\mathrm{RFI}}\right) /\left(\mathrm{A}_{\mathrm{RFI}}-\mathrm{B}_{\mathrm{RFI}}\right) \times\left(\mathrm{A}_{\text {conc. }}-\mathrm{B}_{\text {conc. }}\right)\right]$

where $A_{\text {conc. }}$ is the lowest concentration in $\mu \mathrm{g} / \mathrm{mL}$ with CD69 $\mathrm{RFI} \geq 1.5$; $\mathrm{B}_{\text {conc. }}$ is the highest concentration in $\mu \mathrm{g} / \mathrm{mL}$ with CD69 RFI $<1.5$; $\mathrm{A}_{\mathrm{RFI}}$ is the CD69 RFI at the lowest concentration with $\mathrm{CD} 69 \mathrm{RFI} \geq 1.5$; $\mathrm{B}_{\mathrm{RFI}}$ is the CD69 RFI at the highest concentration with CD69 RFI $<1.5$.

The EC1.5 values are shown in Table 7. For the potency classification, the European Centre for Ecotoxicology and Toxicology of Chemicals (ECETOC) used 1\% of the LLNA EC3 as the threshold to separate strong sensitizers (extreme and strong in LLNA) from weak sensitizers (moderate and weak in LLNA) (ECETOC, 2003; Loveless et al., 2010). The threshold to separate strong sensitizers (extreme and strong in LLNA) from weak sensitizers (moderate and weak in LLNA) in the h-CLAT was $10 \mu \mathrm{g} /$ $\mathrm{mL}$ (Nukada et al., 2012). EC1.5 values in our test were significantly correlated with the minimum induction threshold (MIT) in the h-CLAT $(\mathrm{R}=0.588, \mathrm{P}=0.01)$ (Tab. 7). When $10 \mu \mathrm{g} / \mathrm{mL}$ was also used in our test as the threshold for the classification, the predictivity for the strong sensitizers (extreme and strong in LLNA) was $7 / 9=77.8 \%$, the predictivity for the weak sensitizers (moderate and weak in LLNA) was $16 / 18=88.9 \%$, and the total predictivity was $(7+16) /(9+18)=85.2 \%$. Thus $10 \mu \mathrm{g} / \mathrm{mL}$ may also be an appropriate threshold for our test to separate the strong sensitizers (extreme and strong in LLNA) from the weak sensitizers (moderate and weak in LLNA).

\section{Discussion}

In this study, a novel in vitro test for skin sensitization based on T cell activation was investigated. The Jurkat Clone E6-1 human T cells were incubated directly with the test substances and CD69 expression on the $\mathrm{T}$ cells was determined by flow cytometry to show early $\mathrm{T}$ cell activation induced by sensitizers. No APCs were involved in this model, which made the procedures much simpler than for the other reported assays (Richter et al., 2013; Vocanson et al., 2014). Although no APCs were involved in the 
Tab. 7: Comparison of EC1.5 values of the 27 sensitizers showing a positive response in our study with the EC3 values in LLNA and the MIT values in the $h-C L A T$

\begin{tabular}{|c|c|c|c|c|}
\hline Substances & $\begin{array}{l}\text { LLNA potency } \\
\text { category }\end{array}$ & EC3 in LLNA (\%) & $\begin{array}{l}\text { MIT in h-CLAT } \\
(\mu \mathrm{g} / \mathrm{mL})\end{array}$ & $\begin{array}{l}\text { EC1.5 in our study } \\
(\mu \mathrm{g} / \mathrm{mL}) /(\%)\end{array}$ \\
\hline p-Benzoquinone & extreme & $0.0099^{a}$ & $2.25^{a}$ & $2.36 / 0.000236$ \\
\hline 2,4-Dinitrochlorobenzene & extreme & $0.05^{a}$ & $2.3^{\mathrm{a}}$ & $0.94 / 0.000094$ \\
\hline 4-Nitrobenzyl bromide & extreme & $0.05^{a}$ & $0.91^{a}$ & $0.17 / 0.000017$ \\
\hline Benzo[a]pyrene & extreme & $0.0009^{b}$ & NA & $19.2 / 0.00192$ \\
\hline Glutaraldehyde & strong & $0.1^{\mathrm{a}}$ & $2.7^{\mathrm{a}}$ & $2.17 / 0.000217$ \\
\hline 4-Phenylenediamine & strong & $0.16^{\mathrm{a}}$ & $2.09^{a}$ & $2.48 / 0.000248$ \\
\hline Formaldehyde & strong & $0.61^{a}$ & $4.3^{\mathrm{a}}$ & $4.11 / 0.000411$ \\
\hline Cobalt chloride & strong & $0.38^{a}$ & $35.5^{a}$ & $40.2 / 0.00402$ \\
\hline 4-Methylaminophenol sulfate & strong & $0.8^{c}$ & $12.7^{\mathrm{e}}$ & $2.78 / 0.000278$ \\
\hline Tetramethylthiuram disulfide & moderate & $5.2^{a}$ & $2.46^{a}$ & 3.22 / 0.000322 \\
\hline 2-Methoxy-4-methylphenol & moderate & $5.8^{a}$ & $30.8^{a}$ & $54.2 / 0 / 00542$ \\
\hline Glyoxal & moderate & $1.4^{\mathrm{a}}$ & $286.7^{a}$ & $46.3 / 0.00463$ \\
\hline trans-Cinnamaldehyde & moderate & $1.4^{\mathrm{c}}$ & NA & $4 / 0.0004$ \\
\hline 2-Mercaptobenzothiazole & moderate & $1.7^{\mathrm{a}}$ & $57.5^{a}$ & $69.2 / 0.00692$ \\
\hline m-Aminophenol & moderate & $3.3^{a}$ & $117.1^{a}$ & $39.3 / 0.00393$ \\
\hline Diethyl maleate & moderate & $5.8^{a}$ & $64^{a}$ & $35.7 / 0.00357$ \\
\hline Nickel sulfate & moderate & $4.8^{\mathrm{a}}$ & $42.2^{a}$ & $105.8 / 0.01058$ \\
\hline Resorcinol & moderate & $5.7^{a}$ & $200.9^{a}$ & $207.9 / 0.02079$ \\
\hline Nickel chloride & moderate & $3.5^{d}$ & NA & $56.2 / 0.00562$ \\
\hline Hexyl cinnamic aldehyde & weak & $11^{\mathrm{a}}$ & negative $^{a}$ & $12.7 / 0.00127$ \\
\hline Eugenol & weak & $13^{a}$ & $64.4^{\mathrm{a}}$ & $49.5 / 0.00495$ \\
\hline Phenyl benzoate & weak & $20^{a}$ & $166.2^{a}$ & $61.2 / 0.00612$ \\
\hline Cyclamen aldehyde & weak & $22^{a}$ & negative $^{a}$ & $32.1 / 0.00321$ \\
\hline Hydroxycitronellal & weak & $33^{a}$ & $26.8^{a}$ & $20.0 / 0.002$ \\
\hline Imidazolidinyl urea & weak & $24^{a}$ & $39.3^{a}$ & $90.7 / 0.00907$ \\
\hline Linalool & weak & $30^{a}$ & $68.3^{a}$ & $408.1 / 0.04081$ \\
\hline Ethyl acrylate & weak & $32.8^{c}$ & negative ${ }^{e}$ & $265.4 / 0.02654$ \\
\hline
\end{tabular}

LLNA, murine local lymph node assay; h-CLAT, human cell line activation test; EC3 in LLNA, the concentration needed to produce an SI of 3 in the LLNA; MIT, minimal induction threshold in the h-CLAT; EC1.5 in our study, the concentration at which a test chemical induced a CD69 RFI of 1.5; NA, not available; ${ }^{a}$ data from Nukada et al. (2012); ${ }^{b}$ data from Urbisch et al. (2016); ${ }^{\mathrm{c}}$ data from ICCVAM (2010); ${ }^{\mathrm{d}}$ data from Basketter et al. (2012); ${ }^{\text {e }}$ data from Hoffmann et al. (2018).

model, CD69 expression on the T cells indeed was induced by most of the sensitizers.

It is not the main purpose of this study to determine the mechanisms underlying our test, but we hypothesize the following: (1) During incubation, the sensitizers may bind proteins in the fetal bovine serum contained in the culture medium to form a protein-hapten (chemical) complex containing chemical (hapten) specific epitopes. The epitopes may be the same as those presented in vivo by APCs. (2) The protein-hapten (chemical) complexes may bind the T cell antigen receptors (TCRs) on the Jurkat $\mathrm{T}$ cells directly in this in vitro condition without the aid of APCs. (3) Like a naïve T cell, the Jurkat Clone E6-1 human T cell line expresses CD3 and TCRs and is commonly used in in vitro studies on human T cell activation (Fernández-Riejos et al., 2008; Pan et al., 2015; Ngo et al., 2017; Chen et al., 2018; Vis et al., 2018; Colin-York et al., 2019; Kim et al., 2019). (4) It ap- 
pears that CD69 expression on the surface of T cells is trigged by TCR activation (Testi et al., 1989; Ziegler et al., 1994; Cimo et al., 2013). Thus, upon binding of the protein-hapten (chemical) complexes to the TCRs on the Jurkat cell, the TCRs are activated (i.e., the first signal for $\mathrm{T}$ cell activation), inducing CD69 expression. The second signal for $\mathrm{T}$ cell activation, i.e., co-stimulation of APC-expressed CD80/CD86 and CD28 on T cells does not contribute to CD69 expression in this test model, because there are no APCs in the test system. This hypothesis of the molecular mechanisms will need to be investigated in further studies.

No matter what the molecular mechanisms mediating CD69 expression on the $\mathrm{T}$ cells by the sensitizers in this test model are, we think that this test may be able to predict skin sensitizers based on the following aspects: (1) Most of the 52 chemicals selected were reference substances used previously for challenging in vitro assays for skin sensitization (Sens-it-iv, 2009; Chipinda et al., 2011; Hennen et al., 2011; Emter et al., 2010; Nukada et al., 2012; Natsch et al., 2013). (2) Compared to the vehicle control, most sensitizers tested induced an increase in CD69 expression in the Jurkat Clone E6-1 T lymphocytes. For most sensitizers inducing a positive response, the increases showed a statistically significant linear correlation with the tested concentrations. The statistically significant linear dose-effect relationships could indicate causal links between sensitizers and CD69 expression, supporting the relevance of the test. (3) The concurrent positive control, i.e., $2 \mu \mathrm{g} / \mathrm{mL} \mathrm{DNCB}$, was reproduced in all of the 25 independent runs conducted (Tab. 4), indicating in-house reproducibility of this test model. (4) The accuracy of our test based on the 52 reference chemicals was not statistically significantly different from that of the DPRA, the KeratinoSens ${ }^{\mathrm{TM}}$, the

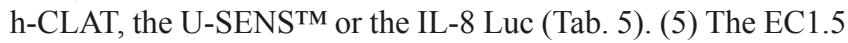
values obtained in this test model may contribute to the assessment of sensitization potency of chemicals in the context of the IATA for skin sensitization.

The predictivity of other T cell based-assays for skin sensitization has been tested based only on a limited number of substances, which mainly were extreme sensitizers (Dietz et al., 2010; Richter et al., 2013; Vocanson et al., 2014; Coulter et al., 2008; Gibson et al., 2015; Ahmed et al., 2016). In contrast, the predictivity of our T cell-based test was assessed based on 52 substances including extreme, strong, moderate and weak sensitizers. Eight of the 11 weak sensitizers were correctly identified as sensitizers. Thus, this test model may have a broad ability to identify sensitizers. The results showed that this test model had a somewhat lower sensitivity and a higher specificity to test sensitizers (Tab. 5).

The magnitude of CD69 expression generally did not correlate with the potency of the sensitizers. For example, the extreme sensitizers oxazolone and 5-chloro-2-methyl-4-isothiazolin-3one showed negative results. In contrast, the highest CD69 RFI value (17.29) was induced by the weak sensitizer hydroxycitronellal (Tab. 3). The mechanisms, which may relate to the TCR repertoire diversity (Esser et al., 2014), are not clear. Possibly, the more epitopes of the chemical that are recognized by TCRs on the T cells, the better the CD69 expression will be induced by the chemical (Esser et al., 2014). Although CD69 expression generally did not correlate with the potency of the sensitizers, the results indicated that the EC1.5 value for each chemical may be used to classify its skin sensitization potency.

Some false predictions occurred in this study, which included 7 sensitizers and 2 non-sensitizers. Of the 7 false-negative sensitizers, oxazolone and 5-chloro-2-methyl-4-isothiazolin-3-one are extreme sensitizers, isoeugenol (prehapten) and cinnamic aldehyde (prehapten) are moderate sensitizers, and cinnamic alcohol (prohapten), citral and methyl methacrylate are weak sensitizers. Sodium lauryl sulfate and salicylic acid were the two false-positives. Except for oxazolone and cinnamic aldehyde, the other 7 falsely predicted chemicals were among the 22 substances of the LLNA performance standards reference substances (ICCVAM, 2010), which reduced the accuracy of our test based only on those 22 substances (63.6\%) compared to its overall accuracy $(82.7 \%)$ based on all 52 substances.

The false predictions occurring in our test show its limitations. We consider that the causes for the false predictions may include the following:

Firstly, the TCR repertoire may be limited in our test as the Jurkat cell line represents only a single "donor". This hypothesis could be investigated by using other $\mathrm{T}$ cell lines from different donors, e.g., five donors as required in the human $\mathrm{T}$ cell priming assay (hTCPA) (Richter et al., 2013).

Secondly, our test does not encompass a metabolic system. As a result, pre- and prohaptens may not be metabolized to reactive derivatives, which may affect their binding to nucleophilic sites in proteins to form hapten-protein complexes. However, although the pre/prohaptens isoeugenol, cinnamic aldehyde and cinnamic alcohol were false-negative in this study, the other pre/prohaptens 2-methoxy-4-methylphenol, benzo[a]pyrene, 4-phenylenediamine, resorcinol, 4-methylaminophenol sulfate, $\mathrm{m}$-aminophenol, eugenol, and linalool showed positive results. Thus, a lack of metabolic capacity does not seem to be a main cause of false-negative results. Also, the OECD-adopted in vitro assays also have limited metabolic capacity, but most pre/ prohaptens are correctly identified by the assays (Nukada et al., 2012, 2013; Emter et al., 2010; Piroird et al., 2015; Takahashi et al., 2011; Kimura et al., 2015, 2018; Patlewicz et al., 2016). However, improving the metabolic capacity by adding rat liver S9 fractions to the KeratinoSens assay or by coculture of $\mathrm{HaCaT}$ keratinocytes with THP-1 in the h-CLAT increased the response to some pre/prohaptens tested (Hennen et al., 2011; Cao et al., 2012; Natsch and Haupt, 2013). Thus, for sensitizers with negative results, improving the metabolic capacity of our test may be considered.

Thirdly, the relevance of our test to represent the complex KE4 of the AOP for skin sensitization may be limited, especially as it does not include APCs. Others already have stated that in vitro assays to assess $\mathrm{T}$ cell activation would inevitably have differences compared to the in vivo conditions (Richter et al., 2013; Vocanson et al., 2014). In spite of this limitation, our test may contribute to the development of an in vitro assay to assess $T$ cell activation based on its good performance in testing 52 chemicals. The molecular mechanisms and related in vivo relevance of our test needs be further clarified. 
Fourthly, the fetal bovine serum used in the test may bind and present the test chemicals differently than human proteins would. Therefore, it could be replaced with human serum in the cell culture medium (Belot et al., 2017) to achieve a fully human model.

Apart from possible technical benefits, replacing fetal bovine serum, bovine serum albumin and animal-derived antibodies with tools that are not derived from animals has benefits for animal welfare. The bovine serum albumin used for blocking in this assay may be replaced by human serum albumin; and the mouse anti-human anti-CD69 antibody used in this assay may be replaced by an antibody from a non-animal source (Edwards et al., 2018). Adapting cells to serum-free culture medium (e.g., HL- ${ }^{\mathrm{TM}}$ and X-VIVO ${ }^{\mathrm{TM}} 10$ ) for cell culture and cryopreservation (Marigliani et al., 2019) may be feasible solutions; however, proteins are essential for the formation of the protein-hapten complex and will need to be included in the test conditions. On the other hand, serum proteins may not be ideal for this purpose, because they contain only $10 \%$ lysine and very few free cysteine residues (OECD, 2012). Moreover, target sites (e.g., cysteine or lysine) located on an exposed surface of a protein are more likely to react with an electrophile than ones located within a grove or fold of a protein. Such steric constraints are imposed by the primary structure (i.e., amino acid sequence) of the peptide or protein, as well as the secondary and tertiary structure of proteins (OECD, 2012). Trying to refine the protein components in the culture medium may improve the prediction of the false negatives in this study.

For the two false positives, sodium lauryl sulfate and salicylic acid, it is difficult to explain why they tested positive in this study. Sodium lauryl sulfate is a surfactant and belongs to the SN2 (substitution nucleophilic bi-molecular) Toxtree protein binding class (Piroird et al., 2015); salicylic acid is a preservative. Both are moderate skin irritants. It could be supposed that their irritant properties disrupted the cell membrane of the Jurkat T cells, which may induce CD69 expression on the cell membrane. In addition, sodium lauryl sulfate showed positive results in the LLNA, the U-SENSTM, the IL-8 Luc (Tab. 5) and other in vitro skin sensitization studies (Herouet et al., 1999; Cumberbatch et al., 2002; Lim et al., 2008; Lee et al., 2020). Salicylic acid showed positive results in the U-SENSTM and the h-CLAT (Tab. 5). It was reported that salicylic acid induced an increase in CD54 expression in THP-1 cells by activation of NLRP3 inflammasomes (Mitachi et al., 2019). Considering that these positive results for sodium lauryl sulfate and salicylic acid appear to relate to different key events of skin sensitization, the relevance of the false-positive results in our study is unclear.

Based on the results of our study and what is discussed above, much work needs to be done to clarify the molecular mechanisms of the test to prove its relevance in modeling KE 4 and to refine the assay to further improve its predictivity.

In conclusion, the performance of a novel in vitro skin sensitization assay based on T lymphocyte activation was tested with 52 reference chemicals. The results indicate that the test may be useful to predict skin sensitizers. This work could contribute to the development of an in vitro assay for skin sensitization based on activation of $\mathrm{T}$ cells.

\section{References}

Ahmed, S. S., Wang. X. N., Fielding. M. et al. (2016). An in vitro human skin test for assessing sensitization potential. $J$ Appl Toxicol 36, 669-684. doi:10.1002/jat.3197

Ashby, J., Hilton, J., Dearman, R. J. et al. (1993). Mechanistic relationship among mutagenicity, skin sensitization, and skin carcinogenicity. Environ Health Perspect 101, 62-67. doi:10.1289/ehp.9310162

Avgustin, B., Kotnik, V., Skoberne, M. et al. (2005). CD69 expression on CD4+ $\mathrm{T}$ lymphocytes after in vitro stimulation with tuberculin is an indicator of immune sensitization against Mycobacterium tuberculosis antigens. Clin Diagn Lab Immunol 12, 101-106. doi:10.1128/CDLI.12.1.101-106.2005

Basketter, D., Kolle, S. N., Schrage, A. et al. (2012). Experience with local lymph node assay performance standards using standard radioactivity and nonradioactive cell count measurements. J Appl Toxicol 32, 590-596 doi:10.1002/jat.1684

Bavandi, A., Fahrngruber, H., Aschauer, H. et al. (2006). Pimecrolimus and tacrolimus differ in their inhibition of lymphocyte activation during the sensitization phase of contact hypersensitivity. J Dermatol Sci 43, 117-126. doi:10.1016/j. jdermsci.2006.04.001

Beeler, A., Zaccaria, L., Kawabata, T. et al. (2008). CD69 upregulation on T cells as an in vitro marker for delayed-type drug hypersensitivity. Allergy 63, 181-188. doi:10.1111/j.1398-9995. 2007.01516.x

Belot, N., Bushra, S., Christopher, L. et al. (2017). Adaptation of the KeratinoSens ${ }^{\mathrm{TM}}$ skin sensitization test to animal-product-free cell culture. ALTEX 34, 560-564. doi:10.14573/altex. 1701311

Cao, Y. P., Ma, P. C., Liu, W. D. et al. (2012). Evaluation of the skin sensitization potential of chemicals in THP-1/keratinocyte co-cultures. Immunopharmacol Immunotoxicol 34, 196204. doi:10.3109/08923973.2011.591800

Casey, W. M. (2016). Advances in the development and validation of test methods in the United States. Toxicol Res 32, 9-14. doi:10.5487/TR.2016.32.1.009

Chakraborty, A. K. and Weiss, A. (2014). Insights into the initiation of TCR signaling. Nat Immunol 15, 798-807. doi:10. 1038/ni.2940

Chen, J., Li, Q., Pang, Z. et al. (2018). Titanium ions promote exogenous calcium-dependent calcium influx in activated Jurkat T cells: A possible mechanism to explain its immunostimulatory properties. Mediators Inflamm 2018, 3286905. doi:10.1155/2018/3286905

Chipinda, I., Ruwona, T. B., Templeton, S. P. et al. (2011). Use of the human monocytic leukemia THP-1 cell line and co-incubation with microsomes to identify and differentiate hapten and prohapten sensitizers. Toxicology 280, 135-143. doi:10.1016/j. tox.2010.12.004

Cho, S. A., Choi, M., Park, S. R. et al. (2020). Application of Spectro-DPRA, KeratinoSens ${ }^{\mathrm{TM}}$ and h-CLAT to estimation of the skin sensitization potential of cosmetics ingredients. $J$ Appl Toxicol 40, 300-312. doi:10.1002/jat.3904

Cimo, A. M., Ahmed, Z., McIntyre, B. W. et al. (2013). CD25 and CD69 induction by $\alpha 4 \beta 1$ outside-in signalling requires 
TCR early signalling complex proteins. Biochem J 454, 109121. doi:10.1042/BJ20130485

Colin-York, H., Kumari, S., Barbieri, L. et al. (2019). Distinct actin cytoskeleton behaviour in primary and immortalised T-cells. J Cell Sci 133, jcs232322. doi:10.1242/jcs.232322

Corsini, E., Papale, A., Galbiati, V. et al. (2014). Safety evaluation of cosmetic ingredients: In vitro opportunities for the identification of contact allergens. Cosmetics 1, 61-74. doi:10.3390/cosmetics1010061

Coulter, E. M., Jenkinson, C., Wu, Y. et al. (2008). Activation of T-cells from allergic patients and volunteers by p-phenyl-enediamine and Bandrowski's base. J Invest Dermatol 128, 897905. doi:10.1038/sj.jid.5701071

Cumberbatch, M., Dearman, R. J., Groves, R. W. et al. (2002). Differential regulation of epidermal Langerhans cell migration by interleukins (IL)- $1 \alpha$ and IL- $1 \beta$ during irritant- and allergen-induced cutaneous immune responses. Toxicol Appl Pharmacol 182, 126-135. doi:10.1006/taap.2002.9442

D’Ambrosio, D., Cantrell, D. A., Frati, L. et al. (1994). Involvement of p21ras activation in T cell CD69 expression. Eur J Immunol 24, 616-620. doi:10.1002/eji.1830240319

Dietz, L., Esser, P. R., Schmucker, S. S. et al. (2010). Tracking human contact allergens: From mass spectrometric identification of peptide-bound reactive small chemicals to chemical-specific naive human T-cell priming. Toxicol Sci 117, 336347. doi:10.1093/toxsci/kfq209

Dimitrova, P., Alipieva, K., Grozdanova, T. et al. (2018). New iridoids from Verbascum nobile and their effect on lectin-induced $\mathrm{T}$ cell activation and proliferation. Food Chem Toxicol 111, 605-615. doi:10.1016/j.fct.2017.11.060

ECETOC (2003). Contact Sensitisation: Classification According to Potency. Technical Report No. 87. European Centre for Ecotoxicology and Toxicology of Chemicals, Brussels, Belgium

Edwards, A., Roscoe, L., Longmore, C. et al. (2018). Adaptation of the human cell line activation test (h-CLAT) to animal-product-free conditions. ALTEX 35, 477-488. doi:10.14573/altex. 1710051

Emter, R., Ellis, G. and Natsch, A. (2010). Performance of a novel keratinocyte-based reporter cell line to screen skin sensitizers in vitro. Toxicol Appl Pharmacol 15, 281-290. doi:10.1016/j.taap.2010.03.009

Esser. P. R., Kimber, I. and Martin, S. F. (2014). Correlation of contact sensitizer potency with T cell frequency and TCR repertoire diversity. Exp Suppl 104, 101-114. doi:10.1007/978-30348-0726-5_8

EU (2009). Regulation (EC) No 1223/2009 of the European Parliament and of the Council of 30 November 2009 on cosmetic products. OJ L342, 59-209. https://eur-lex.europa.eu/eli/ $\mathrm{reg} / 2009 / 1223 / \mathrm{oj}$

Ezendam, J., Braakhuis, H. M. and Vandebriel, R. J. (2016). State of the art in non-animal approaches for skin sensitization testing: From individual test methods towards testing strategies. Arch Toxicol 90, 2861-2883. doi:10.1007/s00204-016-1842-4

Fernández-Riejos, P., Goberna, R. and Sánchez-Margalet, V. (2008). Leptin promotes cell survival and activates Jurkat $T$ lymphocytes by stimulation of mitogen-activated protein ki- nase. Clin Exp Immunol 151, 505-518. doi:10.1111/j.13652249.2007.03563.x

Gibson, A., Kim, S. H., Faulkner, L. et al. (2015). In vitro priming of naïve T-cells with p-phenylenediamine and Bandrowski's base. Chem Res Toxicol 28, 2069-2077. doi:10.1021/acs. chemrestox.5b00294

Green, K. J., Rowbottom, D. G. and Mackinnon, L. T. (2003). Acute exercise and T-lymphocyte expression of the early activation marker CD69. Med Sci Sports Exerc 35, 582-588. doi:10.1249/01.MSS.0000058361.82096.26

Hennen, J., Aeby, P., Goebel, C. et al. (2011). Cross talk between keratinocytes and dendritic cells: Impact on the prediction of sensitization. Toxicol Sci 123, 501-510. doi:10.1093/toxsci/ kfr174

Herouet, C., Cottin, M., Galanaud, P. et al. (1999). Contact sensitizers decrease 33D1 expression on mature Langerhans cells. Eur J Dermatol 9, 185-190.

Hoffmann, S., Kleinstreuer, N., Alépée, N. et al. (2018). Non-animal methods to predict skin sensitization (I): The cosmetics Europe database. Crit Rev Toxicol 48, 344-358. doi:10.1080/ 10408444.2018.1429385

ICCVAM (1999). ICCVAM Test Method Evaluation Report. The Murine Local Lymph Node Assay, a Test Method for Assessing the Allergic Contact Dermatitis Potential of Chemicals/Compounds. NIH Publication No. 99-4494. Research Triangle Park, NC: National Institute of Environmental Health Sciences.

ICCVAM (2010). ICCVAM Test Method Evaluation Report. The Murine Local Lymph Node Assay: BrdU-ELISA, a Nonradioactive Alternative Test Method to Assess the Allergic Contact Dermatitis Potential of Chemicals and Products. NIH Publication No. 10-7552. Research Triangle Park, NC: National Institute of Environmental Health Sciences.

Jaworska, J. S. (2016). Integrated testing strategies for skin sensitization hazard and potency assessment - State of the art and challenges. Cosmetics 3, 16. doi:10.3390/cosmetics3020016

Jowsey, I. R., Basketter, D. A., Westmoreland, C. et al. (2006). A future approach to measuring relative skin sensitising potency: A proposal. J Appl Toxicol 26, 341-350. doi:10.1002/jat.1146

June, C. H., Ledbetter, J. A., Linsley, P. S. et al. (1990). Role of the CD28 receptor in T-cell activation. Immunol Today 11, 211-216. doi:10.1016/0167-5699(90)90085-N

Kim, H. J., Woo, J., Nam, Y. R. et al. (2019). Flos Magnoliae and its constituent linoleic acid suppress $\mathrm{T}$ lymphocyte activation via store-operated calcium entry. Am J Chin Med 29, 1-15. doi:10.1142/S0192415X19500836

Kimura, Y., Fujimura, C., Ito, Y. et al. (2015). Optimization of the IL-8 Luc assay as an in vitro test for skin sensitization. Toxicol In Vitro 29, 1816-1830. doi:10.1016/j.tiv.2015.07.006

Kimura, Y., Fujimura, C., Ito, Y. et al. (2018). Profiling the immunotoxicity of chemicals based on in vitro evaluation by a combination of the Multi-ImmunoTox assay and the IL-8 Luc assay. Arch Toxicol 92, 2043-2054. doi:10.1007/ s00204-018-2199-7

Klug, Y. A., Schwarzer, R., Rotem, E. et al. (2019). The HIV gp41 fusion protein inhibits T-cell activation through the Lentiviral lytic peptide 2 motif. Biochemistry 58, 818-832. 
doi:10.1021/acs.biochem.8b01175

Konrad, A., Rütten, C., Flogerzi, B. et al. (2004). Immune sensitization to yeast antigens in ASCA-positive patients with Crohn's disease. Inflamm Bowel Dis 10, 97-105. doi: 10.1097/00054725-200403000-00006

Koren, A., Silar, M., Rupnik, H. et al. (2019). Quantitative, absolute count-based T-cell analysis of CD69 upregulation as a new methodology for in vitro diagnosis of delayed-type hypersensitivity reaction to nickel. J Investig Allergol Clin Immunol 29, 287-293. doi:10.18176/jiaci.0331

Lee, E., Ahn, S., Jin, S. H. et al. (2020). CXCL14 downregulation in human keratinocytes is a potential biomarker for a novel in vitro skin sensitization test. Toxicol Appl Pharmacol 386, 114828. doi:10.1016/j.taap.2019.114828

Lim, Y. M., Moon, S. J., An, S. S. et al. (2008). Suitability of macrophage inflammatory protein- $1 \beta$ production by THP1 cells in differentiating skin sensitizers from irritant chemicals. Contact Dermatitis 58, 193-198. doi:10.1111/j.16000536.2007.01311.x

Loveless, S. E., Api, A. M., Crevel, R. W. et al. (2010). Potency values from the local lymph node assay: Application to classification, labelling and risk assessment. Regul Toxicol Pharmacol 56, 54-66. doi:10.1016/j.yrtph.2009.08.016

Marigliani, B., Silva, J. V. M. A., Balottin, L. B. L. et al. (2019). Adaptation of a skin sensitization assay to a chemically defined culture. Toxicol In Vitro 57, 145-153. doi:10.1016/j.tiv. 2018.12.004

Mitachi, T., Kouzui, M., Maruyama, R. et al. (2019). Some non-sensitizers upregulate CD54 expression by activation of the NLRP3 inflammasome in THP-1 cells. J Toxicol Sci 44, 213-224. doi: $10.2131 /$ jts.44.213

Morgan, C. D., Greene, J. F. Jr., Measel, J. W. Jr. (1999). Induction of surface antigen CD69 expression in T-lymphocytes following exposure to actinomycin D. Int J Immunopharmacol 21, 689-703. doi:10.1016/S0192-0561(99)00045-4

Natsch, A. and Haupt, T. (2013). Utility of rat liver S9 fractions to study skin-sensitizing prohaptens in a modified KeratinoSens assay. Toxicol Sci 135, 356-368. doi:10.1093/toxsci/kft160 Natsch, A., Ryan, C. A., Foertsch, L. et al. (2013). A dataset on 145 chemicals tested in alternative assays for skin sensitization undergoing prevalidation. J Appl Toxicol 33, 1337-1352. doi:10.1002/jat.2868

Ngo, Q. T., Lee, H. S., Nguyen, V. T. et al. (2017). Chemical constituents from the fruits of Ligustrum japonicum and their inhibitory effects on T cell activation. Phytochemistr 141, 147155. doi:10.1016/j.phytochem.2017.06.001

Nukada, Y., Ashikaga, T., Miyazawa, M. et al. (2012). Prediction of skin sensitization potency of chemicals by human cell line activation test (h-CLAT) and an attempt at classifying skin sensitization potency. Toxicol In Vitro 26, 1150-1160. doi:10.1016/j.tiv.2012.07.001

Nukada, Y., Miyazawa, M., Kazutoshi, S. et al. (2013). Data integration of non-animal tests for the development of a test battery to predict the skinsensitizing potential and potency of chemicals. Toxicol In Vitro 27, 609-618. doi:10.1016/j. tiv.2012.11.006
OECD (1992). Test No. 406: Skin Sensitisation. OECD Guidelines for the Testing of Chemicals, Section 4. OECD Publishing, Paris. doi:10.1787/9789264070660-en

OECD (2010a). Test No. 429: Skin Sensitisation: Local Lymph Node Assay. OECD Guidelines for the Testing of Chemicals, Section 4. OECD Publishing, Paris. doi:10.1787/97 89264071100-en

OECD (2010b). Test No. 442A: Skin Sensitization: Local Lymph Node Assay: DA. OECD Guidelines for the Testing of Chemicals, Section 4. OECD Publishing, Paris. doi:10.1787/ 9789264090972-en

OECD (2010c). Test No. 442B: Skin Sensitization: Local Lymph Node Assay: BrdU-ELISA. OECD Guidelines for the Testing of Chemicals, Section 4. OECD Publishing, Paris. doi:10.1787/9789264090996-en

OECD (2012). The Adverse Outcome Pathway for Skin Sensitisation Initiated by Covalent Binding to Proteins. OECD Series on Testing and Assessment, No. 168. OECD Publishing, Paris. doi:10.1787/9789264221444-en

OECD (2015a). Test No. 442C: In Chemico Skin Sensitisation: Direct Peptide Reactivity Assay (DPRA). OECD Guidelines for the Testing of Chemicals, Section 4. OECD Publishing, Paris. doi:10.1787/9789264229709-en

OECD (2015b). Test No. 442D: In Vitro Skin Sensitisation: ARE-Nrf2 Luciferase Test Method. OECD Guidelines for the Testing of Chemicals, Section 4. OECD Publishing, Paris. doi:10.1787/9789264229822-en

OECD (2016). Guidance Document on the Reporting of Defined Approaches and Individual Information Sources to be Used within Integrated Approaches to Testing and Assessment (IATA) for Skin Sensitisation. OECD Series on Testing and Assessment, No. 256. OECD Publishing, Paris. doi:10.1787/9789264279285-en

OECD (2018). Test No. 442E: In Vitro Skin Sensitization Assays Addressing the Key Event on Activation of Dendritic Cells on the Adverse Outcome Pathway for Skin Sensitization. OECD Guidelines for the Testing of Chemicals, Section 4. OECD Publishing, Paris. doi:10.1787/9789264264359-en

Pan, Y., Wei, X. and Hao, W. (2015). Trichloroethylene and its oxidative metabolites enhance the activated state and Th1 cytokine gene expression in Jurkat cells. Int J Environ Res Public Health 12, 10575-10586. doi:10.3390/ijerph120910575

Patlewicz, G., Casati, S., Basketter, D. A. et al. (2016). Can currently available non-animal methods detect pre and pro-haptens relevant for skin sensitization? Regul Toxicol Pharmacol 82, 147-155. doi:10.1016/j.yrtph.2016.08.007

Piroird, C., Ovigne, J. M., Rousset, F. et al. (2015). The myeloid U937 skin sensitization test (U-SENS) addresses the activation of dendritic cell event in the adverse outcome pathway for skin sensitization. Toxicol In Vitro 29, 901-916. doi:10.1016/j. tiv.2015.03.009

Reisinger, K., Hoffmann, S., Alepee, N. et al. (2015). Systematic evaluation of non-animal test methods for skin sensitisation safety assessment. Toxicol In Vitro 29, 259-270. doi:10.1016/j. tiv.2014.10.018

Richter, A., Schmucker, S. S., Esser, P. R. et al. (2013). Hu- 
man $\mathrm{T}$ cell priming assay (hTCPA) for the identification of contact allergens based on naive T cells and DC - IFN- $\gamma$ and TNF- $\alpha$ readout. Toxicol In Vitro 27, 1180-1185. doi:10.1016/j. tiv.2012.08.007

Robey, E. and Allison, J. P. (1995). T-cell activation: Integration of signals from the antigen receptor and costimulatory molecules. Immunol Today 16, 306-310. doi:10.1016/01675699(95)80140-5

Sens-it-iv list (2009). http://chelist.jrc.ec.europa.eu/index.jsp?id $=2 \&$ id_list $=26$

Strickland, J., Zang, Q., Kleinstreuer, N. et al. (2016). Integrated decision strategies for skin sensitization hazard. J Appl Toxicol 36, 1150-1162. doi:10.1002/jat.3281

Swirski, F. K., Gajewska, B. U., Alvarez, D. et al. (2002). Inhalation of a harmless antigen (ovalbumin) elicits immune activation but divergent immunoglobulin and cytokine activities in mice. Clin Exp Allergy 32, 411-421. doi:10.1046/j.13652222.2002.01291.x

Takahashi, T., Kimura, Y., Saito, R. et al. (2011). An in vitro test to screen skin sensitizers using a stable THP-1-derived IL-8 reporter cell line, THP-G8. Toxicol Sci 124, 359-369. doi:10.1093/toxsci/kfr237

Taylor-Fishwick, D. A. and Siegel, J. N. (1995). Raf-1 provides a dominant but not exclusive signal for the induction of CD69 expression on T cells. Eur J Immunol 25, 3215-3221. doi:10.1002/eji.1830251203

Testi, R., Phillips, J. H. and Lanier, L. L. (1989). Leu 23 induction as an early marker of functional CD3/T cell antigen receptor triggering: Requirement for receptor cross-linking, prolonged elevation of intracellular $\left[\mathrm{Ca}^{++}\right]$and stimulation of protein kinase C. J Immunol 142, 1854-1860.

Urbisch, D., Becker, M., Honarvar, N. et al. (2016). Assessment of pre- and pro-haptens using nonanimal test methods for skin sensitization. Chem Res Toxicol 29, 901-913. doi:10.1021/acs. chemrestox.6b00055

van Vliet, E., Kühnl, J., Goebel, C. et al. (2018). State-of-theart and new options to assess $\mathrm{T}$ cell activation by skin sensitizers: Cosmetics Europe Workshop. ALTEX 35, 179-192. doi:10.14573/altex.1709011

Vis, B., Hewitt, R. E., Faria, N. et al. (2018). Non-functionalized ultrasmall silica nanoparticles directly and size-selectively activate T cells. ACS Nano 12, 10843-10854. doi:10.1021/ acsnano. $8 \mathrm{~b} 03363$

Vocanson, M., Achachi, A., Mutez, V. et al. (2014). Human T cell priming assay: Depletion of peripheral blood lymphocytes in CD25+ cells improves the in vitro detection of weak allergen-specific T cells. Exp Suppl 104, 89-100. doi:10.1007/9783-0348-0726-5 7

Zahid, S., Mustafa, A., Dina, A. et al. (2019). Nickel challenge up regulates CD69 expression on T lymphocyte sub-sets from patients with nickel induced contact dermatitis. Afr Health Sci 19, 1460-1466. doi:10.4314/ahs.v19i1.19

Ziegler, S. F., Ramsdell, F. and Alderson, M. R. (1994). The activation antigen CD69. Stem Cells 12, 456-465. doi:10.1002/ stem.5530120502

\section{Conflict of interest}

The authors declare that there are no conflicts of interest.

\section{Acknowledgements}

This research was sponsored and funded by the National Institute of Occupational Health and Poison Control, Chinese Center for Disease Control and Prevention in 2019 (grant number:19.1.3.1). 